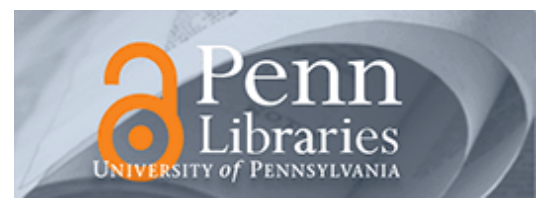

University of Pennsylvania

ScholarlyCommons

Accounting Papers

Wharton Faculty Research

$2-2012$

\title{
The Party's Over: The Role of Earnings Guidance in Resolving Sentiment-Driven Overvaluation
}

Nicholas Seybert

Holly I. Yang

University of Pennsylvania

Follow this and additional works at: https://repository.upenn.edu/accounting_papers

Part of the Accounting Commons, Business Administration, Management, and Operations Commons, and the Marketing Commons

\section{Recommended Citation}

Seybert, N., \& Yang, H. I. (2012). The Party's Over: The Role of Earnings Guidance in Resolving SentimentDriven Overvaluation. Management Science, 58 (2), 308-319. http://dx.doi.org/10.1287/mnsc.1110.1386

At the time of publication, Holly Yang was affiliated with the University of Pennsylvania but she is currently part of the faculty at the Singapore Management University.

This paper is posted at ScholarlyCommons. https://repository.upenn.edu/accounting_papers/96

For more information, please contact repository@pobox.upenn.edu. 


\title{
The Party's Over: The Role of Earnings Guidance in Resolving Sentiment-Driven Overvaluation
}

\begin{abstract}
This paper shows that an important link between investor sentiment and firm overvaluation is optimistic earnings expectations, and that management earnings guidance helps resolve sentiment-driven overvaluation. Using previously identified firm characteristics, we find that most of the negative returns to uncertain firms in months following high-sentiment periods fall within the three-day window around the issuance of management earnings guidance. Comparisons of guidance months to nonguidance months show that guidance issuance affects the magnitude and not just the daily distribution of negative returns. There is also some evidence of negative returns around earnings announcements for firms that previously issued guidance, suggesting that guidance does not entirely correct optimistic earnings expectations. To provide additional insight into the strength of the guidance effect, we show that the market reacts more strongly to surprises, particularly negative surprises, following high-sentiment periods. Finally, firms with higher transient institutional ownership are less likely to guide, and their guidance is less likely to contain bad news following high-sentiment periods, indicating that managers with a short-term focus are hesitant to correct optimistic market expectations.
\end{abstract}

\section{Keywords}

finance, asset pricing, management, earnings guidance, investor sentiment, market efficiency

\section{Disciplines}

Accounting | Business Administration, Management, and Operations | Marketing

\section{Comments}

At the time of publication, Holly Yang was affiliated with the University of Pennsylvania but she is currently part of the faculty at the Singapore Management University. 


\title{
THE PARTY'S OVER: THE ROLE OF EARNINGS GUIDANCE IN RESOLVING SENTIMENT-DRIVEN OVERVALUATION
}

\author{
Nicholas Seybert \\ Robert H. Smith School of Business \\ University of Maryland, College Park \\ nseybert@,rhsmith.umd.edu
}

Holly I. Yang

The Wharton School

University of Pennsylvania

hollyy@,wharton.upenn.edu

May 2, 2011

We thank Brad Barber (editor), an associate editor, two anonymous referees, Brian Bushee, Shuping Chen, Mike Crawley, Chad Ham, Rebecca Hann, Bill Kinney, John McInnis, Jeri Seidman, Kristi Rennekamp, Amanda Wilford, Dan Taylor, and seminar participants at the University of Maryland and the DC Area Accounting Symposium for their helpful comments. We gratefully acknowledge financial support from the University of Maryland's Smith School of Business and the University of Pennsylvania's Wharton School. 


\title{
THE PARTY'S OVER: THE ROLE OF EARNINGS GUIDANCE IN RESOLVING SENTIMENT-DRIVEN OVERVALUATION
}

\begin{abstract}
This paper shows that an important link between investor sentiment and firm overvaluation is optimistic earnings expectations, and that management earnings guidance aids in resolving sentimentdriven overvaluation. Using the firm characteristics identified by Baker and Wurgler (2006), we find that most of the negative returns to uncertain firms in months following high sentiment periods fall within the three-day window around management earnings guidance issuance. Comparisons of guidance months to non-guidance months show that guidance issuance affects the magnitude and not just the daily distribution of negative returns. There is also some evidence of negative returns around earnings announcements for firms that previously issued guidance, suggesting that guidance does not entirely correct optimistic earnings expectations. To provide additional insight into the strength of the guidance effect, we show that the market reacts more strongly to surprises and particularly negative surprises following high sentiment periods. Finally, firms with higher transient institutional ownership are less likely to guide and their guidance is less likely to contain bad news following high sentiment periods, indicating that managers with a short-term focus are hesitant to correct optimistic market expectations.
\end{abstract}




\section{THE PARTY'S OVER: THE ROLE OF EARNINGS GUIDANCE IN RESOLVING SENTIMENT-DRIVEN OVERVALUATION}

\section{Introduction}

Prior research in finance indicates that firms with high valuation uncertainty and/or arbitrage constraints are subject to overvaluation during periods of high investor sentiment. Specifically, Baker and Wurgler $(2006,2007)$ show that younger firms, firms with lower market capitalization, higher return volatility, negative earnings, higher intangible assets, and lower dividends have lower returns in the months following high sentiment periods. ${ }^{1}$ Subsequent studies investigate the effects of investor sentiment on various market participants and find that sentiment affects managers' real investment decisions and analyst earnings optimism (Polk and Sapienza (2009), Hribar and McInnis (2011)). This research also finds that sentiment can predict various stock market anomalies and is more likely to persist in stocks held predominantly by noise traders (Lemmon and Portniaguina (2006), Livnat and Petrovits (2009)). However, while most of these studies provide evidence consistent with stock overvaluation driven by either limits of arbitrage or investor irrationality, none of them demonstrate the process through which the market corrects the prior overvaluation. In this study, we examine whether earnings expectations play a role in sentiment-driven overvaluation by focusing on market reactions to management earnings guidance. Our results indicate that a great deal of the previously documented overvaluation resolves around management earnings guidance, which suggests that earnings expectations are indeed a culprit in sentiment-driven overvaluation.

Understanding the underlying process linking investor sentiment to overvaluation provides insight into investor psychology and difficult-to-predict bull and bear markets. Currently, there are multiple possible explanations for why uncertain stocks are overvalued during high sentiment periods. For example, investors may exhibit different preferences, such as reduced risk aversion, during high sentiment periods, which would lead them to overpay for stocks with high valuation uncertainty. Under this scenario, in subsequent months, a general shift in investing trends or psychology would lead to the gradual decline in prices. Alternatively, investors may engage in a more detailed thought process that involves unrealistic expectations of future firm earnings, where there is more potential to overestimate future earnings for uncertain firms. Under this scenario, in

\footnotetext{
${ }^{1}$ Throughout the paper, we refer to firms that exhibit these seven characteristics as "uncertain" or "difficult to value", and we use these terms interchangeably.
} 
subsequent months, revisions in earnings guidance or other earnings news released by the overvalued firms should lead to predictable price declines. We focus on the second explanation, examining management earnings guidance to test the extent to which the correction of earnings expectations mitigates the overvaluation problem.

In theory, if sentiment reflects investors' irrational expectations about future earnings, then firm-specific earnings information should correct for investors' expectation errors and reduce overvaluation. Consistent with this conjecture, growth stocks and stocks subject to high differences of opinion tend to earn significantly lower returns around earnings announcements (La Porta et al. (1997), Berkman, Dimitrov, Jain, Koch, and Tice (2009)). However, prior investor sentiment research (Baker and Wurgler (2006)) finds only weak evidence that the average earnings announcement return is inversely related to sentiment for the subset of firms that are overvalued (undervalued) when sentiment is high (low). In addition, there is no evidence that earnings announcement effects are any greater than would be expected during a randomly chosen three-day window. We focus on returns around earnings guidance windows because these are important events which provide information to investors about firms' expected performance, prior to the actual earnings announcement. It is well established that guidance events influence both stock prices and analysts' opinions (Matsumoto (2002), Anilowski, Feng, and Skinner (2007), Choi, Myers, Zang, and Ziebart (2010)). Moreover, several recent accounting studies find that guidance events are more important than earnings announcements in conveying information to equity markets (Ball and Shivakumar (2008), Beyer, Cohen, Lys, and Walther (2010)).

We use the First Call Company Issued Guidelines database to delve deeper into the process through which sentiment-driven overvaluation is resolved. Whereas previous studies (Baker and Wurgler (2006), Lemmon and Portniaguina (2006), Baker and Wurgler (2007), Hribar and McInnis (2011)) examine the returns over the subsequent month or quarter depending upon prior investor sentiment, we examine the pattern of returns within those subsequent months. Specifically, we test whether the lower subsequent returns are concentrated around earnings guidance issued by managers of overvalued firms. Like previous studies of sentiment, we find that small firms and young firms, as well as those with high return volatility, high intangible assets, and low dividend payments, have lower monthly returns when prior investor sentiment is high. However, these returns are mostly contained within the three-day window around the issuance of management earnings forecasts. Roughly three-fourths of the predictable negative returns occur in this three day window, while the remaining fourth occurs over the other eighteen trading days in the month. Additionally, returns over entire months during which guidance was not issued are roughly half the 
magnitude of three-day guidance window returns, again suggesting that guidance plays a strong role in price correction. We also find that the market is more sensitive to earnings surprises (particularly negative surprises) following high sentiment periods. However, results from additional tests suggest that managers' attempts to preempt the earnings announcement are not always successful, as we still find some evidence that returns around the three-day earnings announcement window are significantly negative for small and loss firms, and firms with higher volatility following high sentiment periods. Moreover, consistent with Baker and Wurgler (2006), we do not find any systematic evidence that sentiment-driven overvaluation resolves around the three-day earnings announcement window for firms that did not issue guidance. This pattern of results suggests that managers may intentionally issue guidance in an attempt to preempt negative earnings surprises, which could explain why sentiment-driven overvaluation does not resolve around earnings announcements. Consistent with prior work showing that transient institutional ownership induces earnings-related myopia (Bushee (1998)), we find that firms with higher transient ownership are less likely to guide (and their guidance is less likely to contain a negative surprise) following high sentiment periods.

Taken together, our results suggest that earnings expectations play a strong role in sentiment-driven overvaluation. In addition, investors do not appear to ignore bad news when firms are overvalued, but rather exhibit a stronger reaction to bad news forecasts following high sentiment periods. Our findings are important for understanding the nature of investor sentiment and earnings expectations, as well as the effects of management earnings guidance on the market. While prior research on investor sentiment investigates how various agents (managers, investors and analysts) are affected by investor sentiment, none examines the factors that resolve sentimentdriven overvaluation. Our results indicate that investor sentiment does not lead to overvaluation through general beliefs or preferences such as shifts in risk aversion, but rather through firmspecific earnings expectations, a finding which may be relevant to the formulation of hypotheses and research designs in future studies of investor sentiment and market bubbles. Our paper also expands upon prior research investigating the interplay of accounting information and investor sentiment (Bergman and Roychowdhury (2008), Brown et al. (2009), Hribar and McInnis (2011)). Whereas these studies conclude that investor sentiment leads managers (analysts) to intentionally (unintentionally) bias their disclosures and forecasts, our study suggests that management earnings guidance plays a significant role in correcting optimistic market expectations, and thus that firm-specific disclosures also have beneficial effects. Finally, Berkman et al. (2009) find that earnings announcements reduce overvaluation in stocks subject to high short sale constraints and 
high differences of opinion, or in other words in stocks for which valuation difficulty is identifiably high. Our findings suggest that earnings guidance events play an important role in mitigating overvaluation driven by a different source (investor sentiment), suggesting that earnings expectations likely play a broad role in overvaluation and that the disclosure of earnings-related information plays a broad role in mitigating this problem.

The remainder of the paper proceeds as follows. Section II discusses our data sources and key variables. Section III presents our research design and descriptive statistics. Section IV discusses our univariate and regression results, and Section V concludes.

\section{Data Sources and Key Variable Definitions}

\subsection{Sentiment and Characteristics Indicating Overvaluation}

We utilize the monthly sentiment index constructed by the Michigan Consumer Research Center (MCRC). This measure is based on opinion surveys administered to households, and gauges their perceptions of financial well-being, consumer spending, and the strength of the economy. These measures are rated on a scale from 1 to 5 , and are then combined by the MCRC to arrive at an overall monthly measure of sentiment. Prior work supports the use of this measure as a proxy of investor sentiment, as it is highly correlated with actual investor optimism (Qiu and Welch (2006), Bergman and Roychowdhury (2008)). ${ }^{2}$ We conduct cross-sectional tests in low and high sentiment periods using the seven firm characteristics identified by Baker and Wurgler (2006) as being linearly related to firm returns (size, return volatility, earnings, R\&D, PP\&E, dividends and age). As discussed in Section I, these characteristics proxy for valuation uncertainty and/or arbitrage constraints and hence predict sentiment-driven valuation differences.

\subsection{Earnings Guidance}

We use management forecasts of future earnings available from the First Call Company Issued Guidelines (CIG) database beginning in January of 1996 (the first year used in the typical earnings guidance study due to the relative incompleteness of the data in years prior) and ending in December of 2006. We include both quarterly and annual earnings guidance. Because we have a monthly measure of investor sentiment, we match all forecasts made in month to the investor

\footnotetext{
${ }^{2}$ An alternative measure of sentiment introduced by Baker and Wurgler (2007) orthogonalizes macroeconomic factors. While six of the seven firm characteristics load significantly in the predicted direction using the MCRC monthly measure of sentiment, we find in untabulated tests that firm size becomes barely insignificant $(p=0.11)$ using the Baker and Wurgler (2007) monthly measure of sentiment (which is available only through 2005). The remaining five characteristics load significantly in the predicted direction using the Baker and Wurgler measure.
} 
sentiment measure at $t-1$. The database also identifies whether each forecast represents a positive, negative or zero surprise compared to the consensus analyst forecast. We use this variable for our surprise tests. ${ }^{3}$ We also require data to be available on CRSP and COMPUSTAT in order to calculate the guidance window returns, firm size, the book-to-market ratio, and six months prior cumulative returns, as well as the Baker and Wurgler firm characteristics which include (besides size), return volatility, earnings, R\&D expenditure, PP\&E, dividends and age. Moreover, we exclude observations where an earnings announcement is issued within the three-day guidance window to make sure that our results are not driven by market reactions to earnings surprises. ${ }^{4}$ These data requirements result in a final sample size of 31,360 management forecasts, which are issued by a total of 3,883 firms.

\section{Research Design and Descriptive Statistics}

\subsection{Design}

We examine the relation between investor sentiment and guidance window returns using the following model specification:

$$
\begin{aligned}
\operatorname{Car}(-1,+1)= & \alpha+\beta_{1} \text { Size }+\beta_{2} \text { BTM }+\beta_{3} \text { Momentum }+\beta_{4} \text { Sentiment }+\beta_{5} \text { Characteristic } \\
& +\beta_{6} \text { Sentiment } \times \text { Characteristic }+\varepsilon
\end{aligned}
$$

The dependent variable, $\operatorname{Car}(-1,+1)$, is the raw return minus the CRSP value-weighted index cumulative over a three-day window around the issuance of the earnings guidance. ${ }^{5}$ Size is the $\log$ market value of equity at the end of the prior month. BTM is the firm's book value of equity scaled by the market value of equity at the end of the prior month. Momentum is the firm's marketadjusted cumulative return during the prior six months. Sentiment is the decile-ranked MCRC sentiment index, and the key effect of interest is the interaction term, Sentiment $\times$ Characteristic, where Characteristic is one of the seven signals taken from Baker and Wurgler (2006). These characteristics take the form of binary variables for three reasons. First, three of the signals are

\footnotetext{
${ }^{3}$ We include both quantitative and qualitative forecasts in our sample. Qualitative forecasts are forecasts where a company does not provide a specific numerical estimate of earnings. First Call classifies them as zero surprise forecasts unless management indicates that prior expectations are too high or too low. We include them because they are still likely to convey important information to market participants.

${ }^{4}$ In untabulated tests, we find that our results are robust to including guidance events where an earnings announcement was issued within the three-day guidance window.

${ }^{5}$ Returns and control variables are winsorized at the $1 \%$ and $99 \%$ levels to avoid the influence of outliers. Our results are qualitatively identical when we do not winsorize.
} 
naturally binary (dividends vs. no dividends, positive vs. negative earnings, and R\&D vs. no R\&D because many firms have no R\&D expenditure). Second, binary splits make it easy to compare the magnitude of monthly returns and guidance window returns across characteristics in our tables and figures. Third, the four remaining signals exhibit some correlation with sentiment itself, making interactions difficult to interpret. We rank these remaining characteristics (size, return volatility, PP\&E, and age) by month to eliminate this correlation. The firm characteristics are defined as follows: Size is equal to one if the firm is above the median market value of equity at the end of the prior month, and zero otherwise. Volatility is equal to one if the firm is above the median in monthly return volatility over the prior six months, and zero otherwise. Loss is equal to one if the firm experienced negative earnings in the most recent fiscal year, and zero otherwise. $R \& D$ is equal to one if the firm had an R\&D expenditure in the most recent fiscal year, and zero otherwise. $P P \& E$ is equal to one if the firm is above the median plant, property and equipment scaled by total assets in the most recent fiscal year, and zero otherwise. Dividends is equal to one if the firm paid dividends in the most recent fiscal year, and zero otherwise. Age is equal to one if the firm is above the median age in years (measured as the time since the firm first appeared on CRSP), and zero otherwise. All of our regressions are estimated using robust standard errors clustered by month. ${ }^{6}$

\subsection{Descriptive Statistics}

Descriptive statistics are reported in Table 1. The mean market-adjusted guidance window return is $-2.8 \%$, suggesting that earnings guidance lowers market expectations on average during the 1996-2006 sample period. The mean market-adjusted monthly return for the same period is 2.7\%. The mean book-to-market is 0.553 and the mean market-adjusted cumulative six month return (momentum) is $1.8 \%$. As for the Baker and Wurgler (2006) characteristics, the mean return volatility over the prior six months is 0.124 and the mean of the binary loss variable is 0.175 . All of these means are generally consistent with prior studies using a sample of guiding firms (Ajinkya, Bhojraj and Sengupta (2005), Bergman and Roychowdhury (2008)). The remaining firm characteristics also seem reasonable. The mean R\&D expenditure represents $3.2 \%$ of total assets, the mean plant, property and equipment represents $44 \%$ of total assets, approximately $42 \%$ of the firms pay dividends, and the mean firm age is 18 years. Also consistent with prior research, management earnings guidance is more likely to take the form of a negative surprise (Bergman and

\footnotetext{
${ }^{6}$ Our results are unaffected by any of the following: 1. ranking Size, Volatility, $P P \& E$, and Age into deciles, 2. factor analyzing all seven signals and using the first orthogonal factor to represent firm uncertainty, or 3. combining signals linearly into one composite measure using their decile ranks.
} 
Roychowdhury (2008)). Negative surprises occur around 31\% of the time while positive surprises occur around $12 \%$ of the time. ${ }^{7}$

\section{[Insert Table 1]}

Table 2 presents correlation coefficients for the dependent and independent variables. As previously mentioned, some of the firm characteristics are weakly correlated with investor sentiment. Ranking Size, Volatility, PP\&E, and Age by month alleviates this issue. Interestingly, investor sentiment is also correlated with the surprise variables - high sentiment months are less likely to be followed by positive surprises and more likely to be followed by negative surprises.

[Insert Table 2]

\section{Results}

\subsection{The Effect of Sentiment on Guidance Window Returns Controlling for Characteristics}

We first examine whether investor sentiment and firm characteristics predict guidance window returns after controlling for size, book-to-market and momentum. As previously discussed, we use three-day cumulative market-adjusted returns centered on management guidance issuance dates. Results are displayed in Table 3 for all seven characteristics. For brevity, the coefficients for size, book-to-market, and momentum are not reported. The key effects of interest are the Sentiment $\times$ Characteristic interactions. To be consistent with prior research and theory, the expected interaction coefficients are positive for size, PP\&E, dividends and age, and negative for volatility, losses and R\&D. For six of seven regressions, the interaction coefficient is significant in the expected direction (the effect of loss is not significant). Because Sentiment is decile ranked and each characteristic is binary, the coefficients can be interpreted as the effect of a one decile increase in investor sentiment on the three-day window return difference between low- and high-uncertainty firms. The effect of moving from the bottom to the top sentiment decile ranges in magnitude from roughly $1.8 \%$ for firm size to $4.14 \%$ for return volatility, with other characteristics falling in between. Interestingly, the coefficient on Sentiment is also negative and significant in each regression, suggesting that market reactions are generally more negative to earnings guidance

\footnotetext{
${ }^{7}$ The remaining sample consists of forecasts that First Call identify as guidance issuances that do not qualify as a surprise, either because the firm forecast is equal to the prior analyst consensus, the range forecast contains the prior analyst consensus, there was no current analyst forecast to compare the firm forecast to, or the forecast was a qualitative forecast indicating that management was "okay with expectations."
} 
following high sentiment periods. These results suggest that earnings expectations play a role in sentiment-driven overvaluation.

[Insert Table 3]

\subsection{Comparing Guidance Window Returns to Total Monthly Returns}

To test the relative importance of earnings guidance in the months subsequent to high sentiment periods, we run the same regressions with returns outside of the guidance window (the remaining eighteen trading days in the month) on the left hand side and compare the interaction coefficients to the coefficients for the three-day guidance window returns. Table 4 displays the effect of a one-decile increase in lagged sentiment on three-day guidance window (first column) and returns over the remaining eighteen trading days (second column) for each of the seven characteristics. Again, based upon the results of prior sentiment research (Baker and Wurgler (2006)), we expect guidance window returns to be more negative following high sentiment (compared to low sentiment) periods for these characteristic differences: small - big, high volatility - low volatility, loss - profit, R\&D - no R\&D, low PP\&E - high PP\&E, dividend nonpayer dividend payer, and young - old. While the effect of a one-decile increase in lagged sentiment is associated with a three-day guidance window return of $-0.30 \%$, the effect on the remaining eighteen trading days is merely $-0.08 \%$. We also compare the monthly short-long hedge portfolio returns for months without guidance issuance. The third column displays the returns for months in which no earnings guidance is issued by the same 3,883 firms over the 1996-2006 sample period. The average effect of a one-decile increase in lagged sentiment is $-0.16 \%$, just over half the magnitude of the three-day guidance window effect, which reinforces the importance of guidance events in resolving sentiment-driven overvaluation.

\section{[Insert Table 4]}

The plots in Figure 1 present the market-adjusted return patterns more tellingly. The 21day return window around guidance issuance is plotted for low- and high-uncertainty firms and for low- (below the median) and high- (above the median) lagged sentiment. As can be seen, the strongest negative guidance window return is uniformly concentrated in firms with higher uncertainty following high sentiment periods. While there does appear to be some evidence of very slightly lower returns for these firms in the first week, the most stark differences are concentrated 
in the three-day guidance window. Following the guidance window, there is no clear difference in returns among the four groups. These results provide additional evidence that earnings expectations are a major link between investor sentiment and firm overvaluation. Once earnings guidance is released, the market appears to revert to more accurate firm valuations.

\section{[Insert Figure 1]}

\subsection{The Effect of Sentiment on Earnings Announcement Window Returns Controlling for Characteristics}

Thus far, our results are consistent with earnings expectations playing a role in sentimentdriven overvaluation, and provide a plausible alternative explanation for why Baker and Wurgler (2006) only find weak evidence of overvaluation resolving around earnings announcement windows. If information that would otherwise be released via an earnings announcement is already communicated through the management forecast, then this suggests that there should not be a negative market reaction around earnings announcement windows for high uncertainty firms following high sentiment periods. Therefore, we examine returns around earnings announcement windows for both preempted and non-preempted earnings announcements in this section. We define (non)preempted earnings announcements as those (not) preceded by at least one management forecast prior to the three-day earnings announcement window. We replace the dependent variable in model (1) with $\operatorname{EACAR}(-1,+1)$ where $\operatorname{EACAR}(-1,+1)$ is the cumulative marketadjusted three-day return centered around the earnings announcement date. The results for this analysis are presented in Table 5. For brevity, we only present coefficients on the interaction terms.

The first row of Table 5 presents results for the sample of firms where the earnings announcement was preceded by at least one management forecast. Consistent with earnings guidance moving information forward that would otherwise be released at the earnings announcement, the returns are no longer significant for R\&D, PP\&E, Dividends, and Age. However, the results also suggest that small, high volatility, and loss firms earn significantly lower returns around earnings announcement windows. The second row of Table 5 presents results for the nonpreempted sample. While the coefficients are all in the expected direction, we do not find robust evidence that returns are significantly negative around earnings announcement windows for the seven firm characteristics. This may be because managers intentionally attempt to preempt bad earnings announcement news, such that the absence of earnings guidance is evidence of the 
absence of unrevealed bad news. ${ }^{8}$ Taken together, these results suggest that while earnings guidance plays a role in resolving sentiment-driven overvaluation, managers are not always successful in preempting the negative reaction at the earnings announcement.

[Insert Table 5]

\subsection{The Effect of Sentiment on Market Reactions to Positive and Negative Guidance Surprises}

The negative market reaction to guidance from high uncertainty firms following high sentiment periods suggests that market reactions to negative surprises may be stronger following high sentiment periods. To test this possibility, we use the following model:

$$
\begin{aligned}
\operatorname{Car}(-1,+1)= & \alpha+\beta_{1} \text { Size }+\beta_{2} \text { BTM }+\beta_{3} \text { Momentum }+\beta_{4} \text { Sentiment }+\beta_{5} \text { PosSurp } \\
& +\beta_{6} \text { Sentiment } \times \text { PosSurp }+\beta_{7} \text { NegSurp }+\beta_{8} \text { Sentiment } \times \text { NegSurp } \\
& +\varepsilon
\end{aligned}
$$

PosSurp is a binary variable equal to one if the earnings guidance represents a positive surprise (higher than the prior analyst consensus forecast, as defined on First Call), and zero otherwise. NegSurp is a binary variable equal to one if the earnings guidance represents a negative surprise (lower than the prior analyst consensus forecast, as defined on First Call), and zero otherwise. All other variables are as previously defined. All models use robust standard errors clustered by month. The key effects of interest are the sentiment by surprise interactions. If the market exhibits increased sensitivity to earnings guidance, the positive surprise interaction should be significantly positive, while the negative surprise interaction should be significantly negative.

Table 6 displays results for model (2). Positive surprises garner a stronger reaction following high sentiment periods as evidenced by the interaction coefficient, which indicates that each decile increase in sentiment leads to a $0.28 \%$ higher three-day return for positive surprises. Similarly, negative surprises also garner a stronger reaction following high sentiment periods which appears to be even stronger than the effect on positive surprises. The coefficient on the interaction term indicates that each decile increase in sentiment leads to a $0.64 \%$ lower three-day return for negative surprises. These results suggest that increases in investor sentiment will predominantly lead to stronger negative market reactions to earnings guidance. This result is

\footnotetext{
${ }^{8}$ We examine management incentives to preempt bad news in high sentiment periods in section 4.5.
} 
consistent with market earnings expectations being higher during high sentiment periods, and with negative surprises correcting the overvaluation that these expectations create. ${ }^{9}$

[Insert Table 6]

\subsection{The Effect of Investor Myopia on Guidance Decisions}

The prior section documents a statistically significant association between sentiment and market reactions to bad news earnings guidance. In this section, we examine whether managers have incentives to withhold bad news during high sentiment periods. Prior research suggests that there is a strong link between firms' disclosure practices and their composition of institutional ownership (Bushee and Noe (2000)). For example, transient institutional investors who have shorter investment horizons invest more heavily in firms with more frequent disclosures because forthcoming disclosure practices reduce information asymmetry and lessen the price impact on trades. On the other hand, if management is aware that transient investors will immediately reduce their holdings when bad news is issued, then this may lead management to suppress bad news when earnings expectations are higher during high sentiment periods. Consistent with this idea, Bushee (1998) shows that higher transient ownership induces managers to make myopic decisions in order to present more positive earnings news. To test whether investor myopia affects management guidance decisions, we utilize the following model:

$$
\begin{aligned}
\operatorname{Pr}(\text { Disclose })= & \alpha+\beta_{1} \text { Size }+\beta_{2} \text { BTM }+\beta_{3} \text { Momentum }+\beta_{4} \text { Sentiment }+\beta_{5} \text { Transient } \\
& +\beta_{6} \text { Sentiment } \times \text { Transient }+\varepsilon
\end{aligned}
$$

Disclose is a binary variable equal to one if the firm issued at least one management forecast prior to the actual earnings announcement, and zero otherwise. Transient is a binary variable equal to one if the level of transient institutional investor holdings is above the median, and zero otherwise. We identify transient institutional investors using the Bushee (1998) classification method and measure institutional holdings at the quarterly level. The first column of Table 7

\footnotetext{
${ }^{9}$ In untabulated analyses, we also test whether guidance is more likely to represent a negative surprise for overvalued firms following high sentiment periods, which would also explain the strong effect of guidance reactions in resolving sentiment-driven overvaluation. Consistent with our expectations, we find that size and PP\&E are negatively correlated with the issuance of a negative surprise while volatility and R\&D are positively correlated with a negative surprise. Similarly, volatility, loss and R\&D are negatively correlated with a positive surprise, while PP\&E, age and dividends are positively correlated with a positive surprise.
} 
presents the regression results for model (3). The coefficient on Sentiment is negative and significant $\left(\beta_{4}=-0.0714, p<0.01\right)$, consistent with Bergman and Roychowdhury (2008). Consistent with Bushee and Noe (2000), we also find a positive association between high transient institutional ownership and the likelihood of disclosure $\left(\beta_{5}=0.480, p<0.01\right)$. Moreover, the coefficient on the interaction term is significantly negative $\left(\beta_{6}=-0.0301, p<0.01\right)$, which suggests that firms with high transient institutional ownership are less likely to disclose when sentiment is high.

To provide further evidence that management has incentives to suppress bad news when earnings expectations are high, we examine the effect of sentiment and investor myopia on the likelihood of good and bad news disclosures, and estimate a variation of model (3) with NegSurp and PosSurp on the left hand side. The results for this analysis are provided in the last two columns of Table 7. The negative coefficient $\left(\beta_{6}=-0.0271, p<0.05\right)$ on the interaction terms suggest that high transient institutional ownership firms are less likely to issue guidance that is below prevailing analysts' consensus in high sentiment periods. However, we do not find that they are more likely to issue good news when sentiment is high. Overall, these findings are consistent with investor myopia and optimistic market expectations influencing managers' disclosure behavior. Firms with greater transient institutional holdings are less likely to provide (bad news) guidance to dampen earnings expectations when investor sentiment is high.

[Insert Table 7]

\section{Conclusion}

Our results indicate that market reactions to management guidance are more negative for firms facing high uncertainty and/or arbitrage constraints following high sentiment periods. The three-day guidance window returns represent the majority of monthly negative returns. We also find some evidence that earnings guidance moves forward information that would otherwise be released at the earnings announcement, but does not always fully preempt negative earnings announcement news. In addition, the market reacts more strongly to negative surprises contained in earnings guidance following high sentiment periods, and managers are hesitant to correct market expectations when they have a myopic investor base. Taken together, these results suggest that optimistic earnings expectations play a strong role in sentiment-driven overvaluation and that earnings guidance plays an important role in mitigating this effect. 
This study contributes to several streams of research. First, our results shed light on the market psychology behind sentiment-driven overvaluation, which should be relevant for future studies of investor sentiment and investor behavior more generally. We also contribute to the management guidance literature by showing that earnings guidance can correct market expectations at critical times. Our results contrast with those of prior accounting research, which suggests that managers withhold their private information to exacerbate rather than attenuate overvaluation (Bergman and Roychowdhury (2008)), which should provide a more balanced picture to researchers in this area. Together, our results suggest that while managers may reduce their disclosure frequency during high sentiment periods, the disclosures actually help make prices more efficient by reducing overvaluation and resolving uncertainty.

An important caveat to our findings and interpretation is that while prior finance research suggests that negative returns following high sentiment periods represent overvaluation, our findings do not necessarily imply market inefficiency beyond limits to arbitrage. As previously discussed, many of the valuation uncertainty variables are also posited to proxy for short-sale constraints (e.g., small firms with high intangibles and poor earnings), which would make arbitrage difficult during high sentiment periods.

The results point toward a variety of directions for future research. Future studies could attempt to delve deeper into managers' incentives to determine when guidance most contributes to resolving overvaluation, investigating the effects of stock option compensation, litigation risk, or information asymmetry. Research could also test whether firms who issue guidance during these critical periods benefit from increased future disclosure credibility in the eyes of investors. It would also be interesting to examine returns around other events that may influence earnings expectations, such as articles in the financial press or negative analyst forecast revisions. All of these issues may be fruitful topics for future research. 


\section{References}

Ajinkya, B., Bhojraj, S., and Sengupta, P. 2005. The association between outside directors, institutional investors, and the properties of management earnings forecasts. Journal of Accounting Research, 43(3), 343-376.

Anilowski, C., Feng, M., and Skinner, D. 2007. Does earnings guidance affect market returns? The nature and information content of aggregate earnings guidance. Journal of Accounting and Economics, 44(1), 36-63.

Baker, M., and Wurgler, J. 2006. Investor sentiment and the cross-section of stock returns. Journal of Finance, 61(4), 1645-1680.

Baker, M., and Wurgler, J. 2007. Investor sentiment in the stock market. Journal of Economic Perspectives, 21(2), 129-151.

Ball, R., and Shivakumar, L. 2008. How much new information is there in earnings? Journal of Accounting Research, 46(5), 975-1016.

Bergman, N., and Roychowdhury, S. 2008. Investor sentiment and corporate disclosure. Journal of Accounting Research, 46(5), 1057-1083.

Berkman, H., Dimitrov, V., Jain, P., Koch, P., and Tice, S. 2009. Sell on the news: Differences of opinion, short-sales constraints, and returns around earnings announcements. Journal of Financial Economics, 92(3), 376-399.

Beyer, A., Cohen, D., Lys, T., and Walther, B. 2010. The financial reporting environment: Review of the recent literature. Forthcoming, Journal of Accounting and Economics.

Brown, N., Christensen, T., Elliott, B., and Mergenthaler, R. 2009. Do managers use pro forma earnings disclosures to cater to investor sentiment? Working paper, University of Southern California.

Bushee, B. J. 1998. The influence of institutional investors on myopic R\&D behavior. Accounting Review, 73, 19-45.

Bushee, B. J., and Noe, C. F. 2000. Corporate disclosure practices, institutional investors, and stock return volatility. Journal of Accounting Research, 38 Supplement, 171-202.

Choi, J., Myers, L., Zang, Y., and Ziebart, D. 2010. Do management EPS forecasts allow returns to reflect future earnings? Implications for the continuation of management's quarterly earnings guidance. Forthcoming, Review of Accounting Studies.

Hribar, P., and McInnis, J. 2011. Investor sentiment and analysts' earnings forecast errors. Forthcoming, Management Science. 
La Porta, R., Lakonishok, J., Shleifer, A., and Vishny, R. 1997. Good news for value stocks: further evidence on market efficiency. Journal of Finance, 52(2), 859-874.

Lemmon, M., and Portniaguina, E. 2006. Consumer confidence and asset prices: Some empirical evidence. Review of Financial Studies, 19(4), 1499-1529.

Livnat, J., and Petrovits, C. 2009. Investor sentiment, post-earnings announcement drift, and accruals. Working paper, New York University.

Matsumoto, D. 2002. Management's incentives to avoid negative earnings surprises. The Accounting Review, 77(3), 483-514.

Polk, C., and Sapienza, P. 2009. The stock market and corporate investment: A test of catering theory. Review of Financial Studies, 22(1), 187-217.

Qiu, L., and Welch, I. 2006. Investor sentiment measures. Working paper, Brown University. 

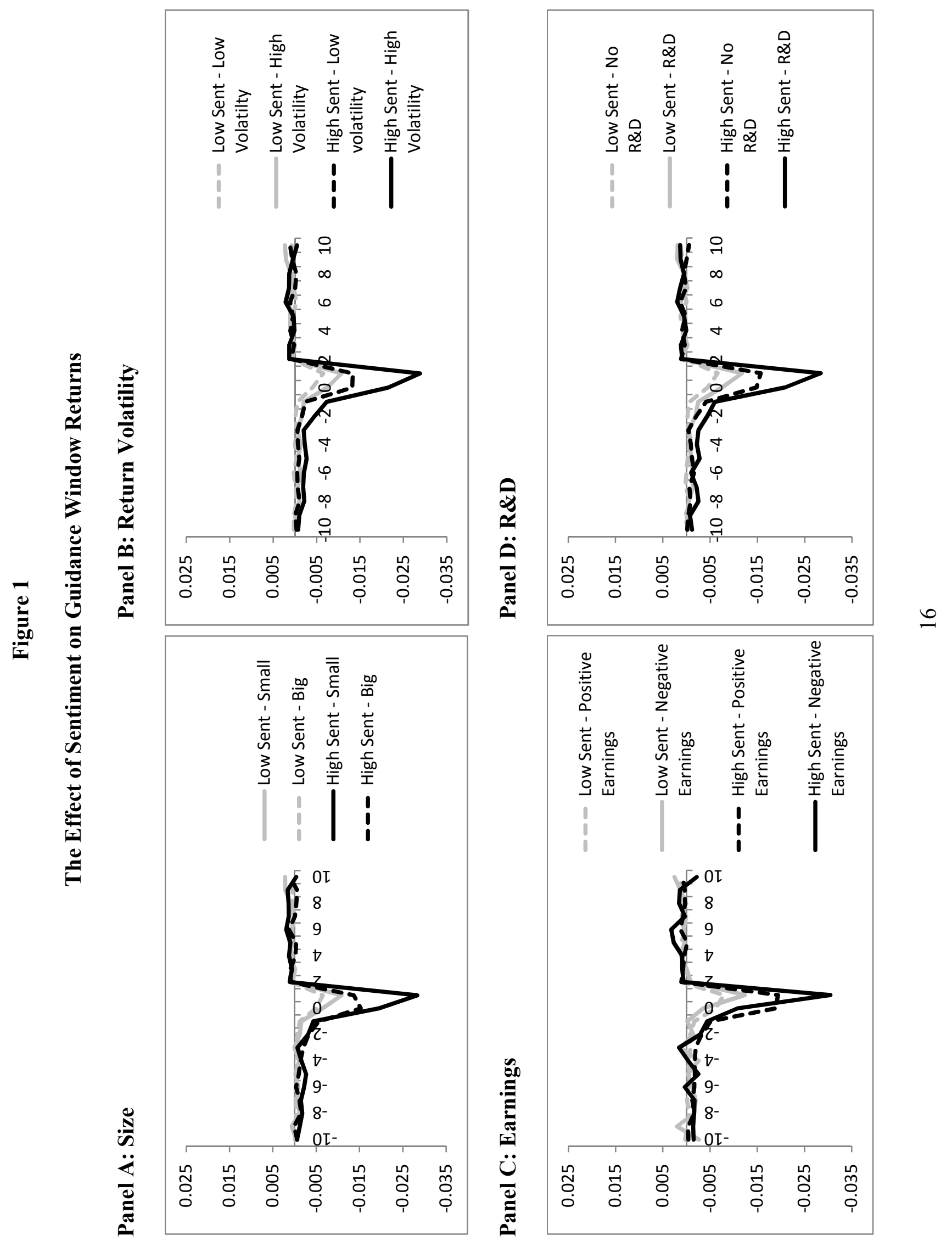

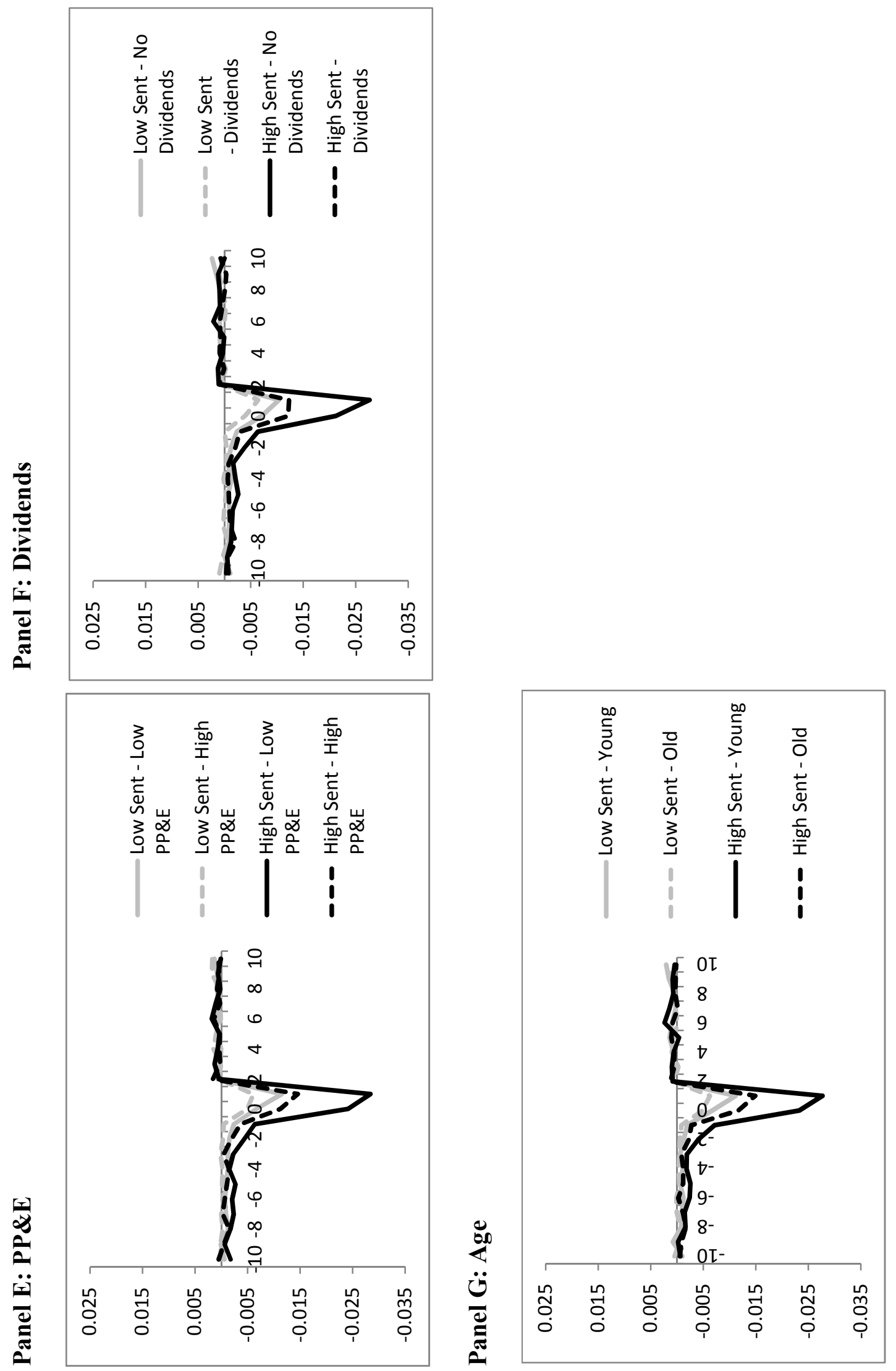

I 


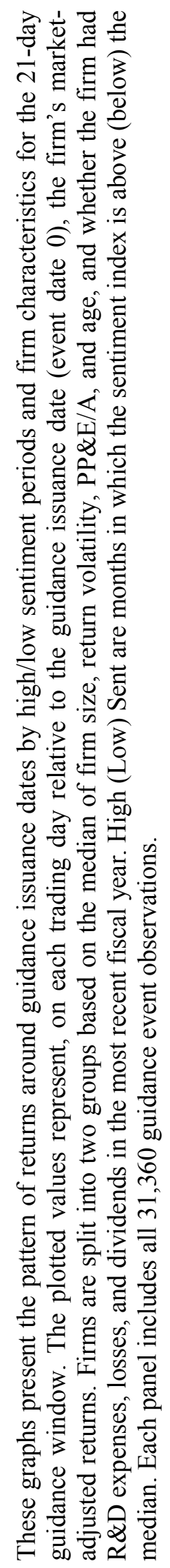




\section{Table 1}

\section{Descriptive Statistics}

\begin{tabular}{lcrrrrr}
\hline Variable & N & \multicolumn{1}{c}{ Mean } & \multicolumn{1}{c}{ Q1 } & \multicolumn{1}{c}{ Median } & \multicolumn{1}{c}{ Q3 } & Std. Dev \\
\hline Car(-1,+1) & 31,360 & -0.028 & -0.073 & -0.010 & 0.032 & 0.132 \\
MonthRet & 31,360 & -0.027 & -0.114 & -0.017 & 0.063 & 0.200 \\
Size & 31,360 & 13.682 & 12.404 & 13.562 & 14.877 & 1.858 \\
BTM & 31,360 & 0.553 & 0.247 & 0.422 & 0.687 & 0.511 \\
Momentum & 31,360 & 0.018 & -0.197 & -0.014 & 0.171 & 0.369 \\
Sentiment & 31,360 & 94.673 & 88.800 & 93.700 & 102.700 & 8.564 \\
Volatility & 31,360 & 0.124 & 0.066 & 0.100 & 0.155 & 0.111 \\
Loss & 31,360 & 0.175 & 0.000 & 0.000 & 0.000 & 0.380 \\
R\&D/A & 31,360 & 0.032 & 0.000 & 0.000 & 0.036 & 0.068 \\
PP\&E/A & 31,360 & 0.441 & 0.171 & 0.375 & 0.634 & 0.344 \\
Dividends & 31,360 & 0.418 & 0.000 & 0.000 & 1.000 & 0.493 \\
Age & 31,360 & 18.096 & 5.000 & 11.000 & 26.000 & 18.677 \\
PosSurp & 31,360 & 0.117 & 0.000 & 0.000 & 0.000 & 0.322 \\
NegSurp & 31,360 & 0.305 & 0.000 & 0.000 & 1.000 & 0.461 \\
\hline
\end{tabular}

This table presents summary statistics for our dependent and independent variables. $C A R(-1,+1)$ is the cumulative market-adjusted 3 day return centered around the earnings guidance issuance date. MonthRet is market-adjusted monthly return. Size is the log market value of equity at the end of the prior month. $B T M$ is the firm's book value of equity scaled by the market value of equity at the end of the prior month. Momentum is the firm's cumulative marketed-adjusted return during the prior six months. Sentiment is the monthly MCRC sentiment index measure. Volatility is monthly return volatility over the prior six months. Loss is a binary variable equal to one if the firm experienced negative earnings in the most recent fiscal year, and zero otherwise. $R \& D / A$ is the firm's $R \& D$ expense scaled by total assets during the most recent fiscal year. $P P \& E / A$ is the firm's plant, property, and equipment scaled by total assets during the most recent fiscal year. Dividends is a binary variable equal to one if the firm paid dividends during the most recent fiscal year, and zero otherwise. Age is firm age. PosSurp is a binary variable equal to one if the earnings guidance is higher than the prior analyst consensus forecast, and zero otherwise. NegSurp is a binary variable equal to one if the earnings guidance is lower than the prior analyst consensus forecast, and zero otherwise. 


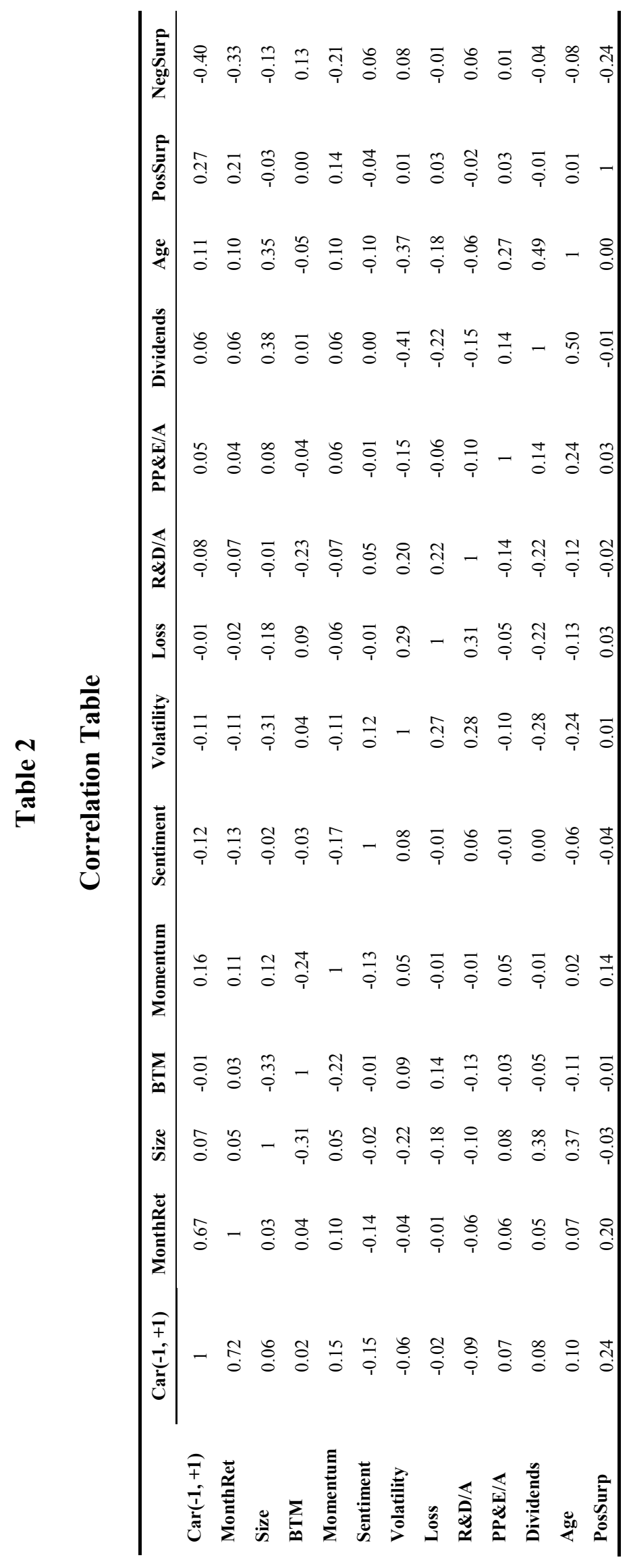

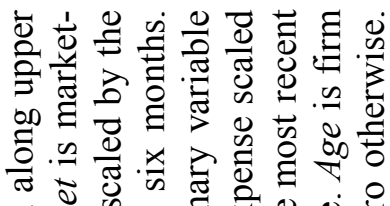

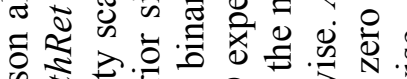
记

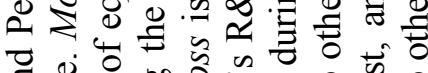

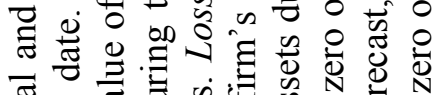

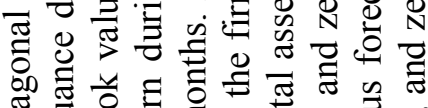

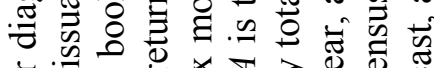

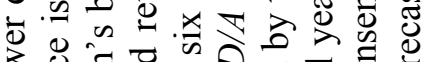

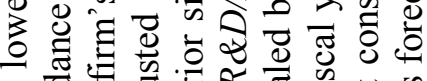

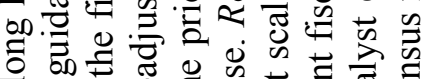
음 สี

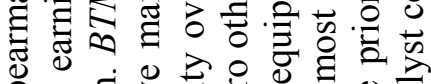

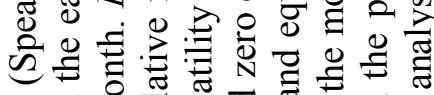

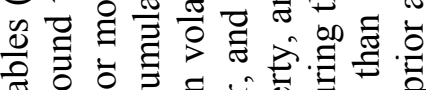

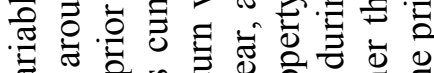

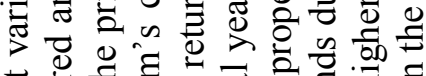

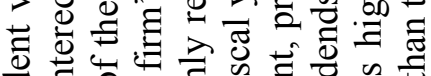

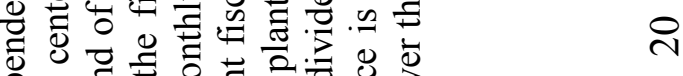
过

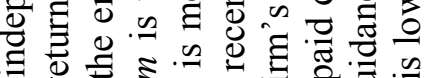

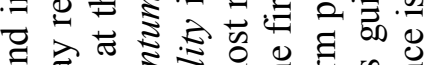

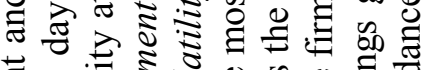

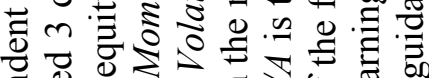

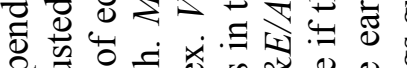

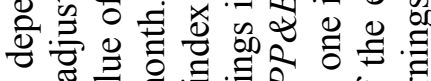

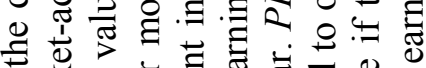

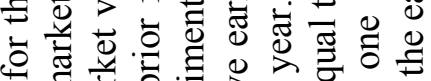

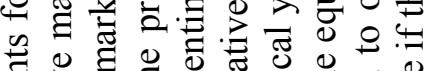

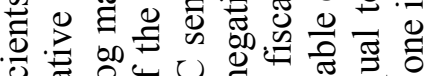

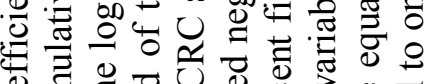

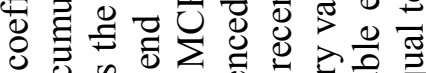

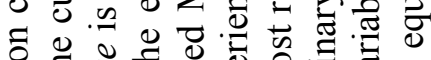

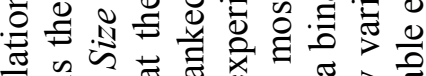
䨔.

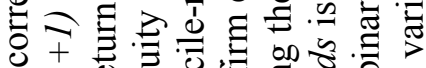

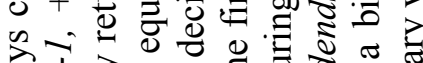

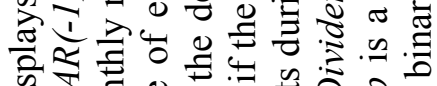

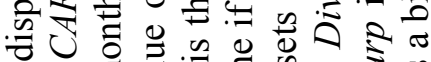

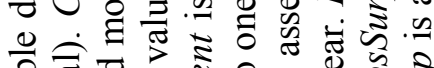

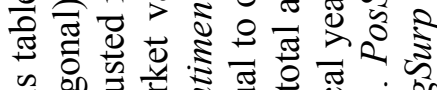

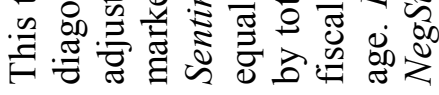




\section{Table 3}

\section{The Effect of Sentiment on Guidance Window Returns}

\begin{tabular}{|c|c|c|c|c|c|c|c|}
\hline & \multicolumn{7}{|c|}{ Dependent Variable: CAR $(-1,+1)$} \\
\hline & Size & Volatility & Earnings & $R \& D$ & PP\&E & Dividends & Age \\
\hline Sentiment & $\begin{array}{c}-0.0056^{* * *} \\
(0.0009)\end{array}$ & $\begin{array}{c}-0.0023 * * * \\
(0.0007)\end{array}$ & $\begin{array}{c}-0.0044 * * * \\
(0.0007)\end{array}$ & $\begin{array}{c}-0.0036^{* * *} \\
(0.0008)\end{array}$ & $\begin{array}{c}-0.0062 * * * \\
(0.0009)\end{array}$ & $\begin{array}{c}-0.0063 * * * \\
(0.0009)\end{array}$ & $\begin{array}{c}-0.0064 * * * \\
(0.0009)\end{array}$ \\
\hline Sent*Size & $\begin{array}{c}0.0020^{* * *} \\
(0.0006)\end{array}$ & & & & & & \\
\hline Volatility & & $\begin{array}{c}0.0043 \\
(0.0035)\end{array}$ & & & & & \\
\hline Sent*Volatility & & $\begin{array}{c}-0.0046^{* * *} \\
(0.0008)\end{array}$ & & & & & \\
\hline Loss & & & $\begin{array}{c}0.0060 \\
(0.0047)\end{array}$ & & & & \\
\hline Sent*Loss & & & $\begin{array}{l}-0.0011 \\
(0.0011)\end{array}$ & & & & \\
\hline $\mathrm{R} \& \mathrm{D}$ & & & & $\begin{array}{l}-0.0021 \\
(0.0041)\end{array}$ & & & \\
\hline Sent*R\&D & & & & $\begin{array}{c}-0.0022 * * \\
(0.0009)\end{array}$ & & & \\
\hline PP\&E & & & & & $\begin{array}{c}0.0023 \\
(0.0037)\end{array}$ & & \\
\hline Sent*PP\&E & & & & & $\begin{array}{c}0.0033^{* * *} \\
(0.0008)\end{array}$ & & \\
\hline Dividends & & & & & & $\begin{array}{l}-0.0013 \\
(0.0034)\end{array}$ & \\
\hline Sent*Dividends & & & & & & $\begin{array}{c}0.0038 * * * \\
(0.0007)\end{array}$ & \\
\hline Age & & & & & & & $\begin{array}{l}-0.0005 \\
(0.0034)\end{array}$ \\
\hline Sent*Age & & & & & & & $\begin{array}{c}0.0035 * * * \\
(0.0007)\end{array}$ \\
\hline Observations & 31,360 & 31,360 & 31,360 & 31,360 & 31,360 & 31,360 & 31,360 \\
\hline R-squared & 0.038 & 0.043 & 0.038 & 0.040 & 0.042 & 0.042 & 0.041 \\
\hline
\end{tabular}

These regressions test the effects of firm overvaluation in periods of low and high sentiment on guidance window returns after controlling for size, book-to-market, and momentum. $C A R(-1,+1)$ is the marketadjusted 3 day return centered around the earnings guidance issuance date. Sentiment is the decile-ranked MCRC sentiment index in the prior month. See Table 2 for variable definitions. When interacted with Sentiment, Size, Volatility, $P P \& E$, and Age are coded as one if above the median, and zero otherwise, while Loss, $R \& D$, and Dividends are coded as a one when present and zero when absent. Robust standard errors clustered by month are displayed in parentheses. Coefficients marked with $\mathrm{a} *, * *$, or $* * *$ are significant at $\mathrm{p}$ $<.10, .05$, or .01 , respectively. 


\section{Table 4}

\section{Comparing the Effect of Sentiment on Guidance and Non-Guidance Returns}

\begin{tabular}{lccc}
\hline \multirow{2}{*}{\multicolumn{1}{c}{ Characteristic }} & \multicolumn{3}{c}{ Effect of Decile-Ranked Sentiment } \\
\cline { 2 - 4 } & $\begin{array}{c}\text { Three-Day } \\
\text { Guidance Window }\end{array}$ & $\begin{array}{c}\text { Remaining Eighteen Days } \\
\text { of Guidance Month }\end{array}$ & $\begin{array}{c}\text { Non-Guidance } \\
\text { Month }\end{array}$ \\
\hline Size (small - big) & $-0.20 \%$ & $-0.03 \%$ & $-0.21 \%$ \\
Volatility (high - low) & $-0.46 \%$ & $-0.23 \%$ & $-0.20 \%$ \\
Earnings (loss - profit) & $-0.11 \%$ & $0.10 \%$ & $-0.26 \%$ \\
R\&D (expense - no expense) & $-0.22 \%$ & $-0.05 \%$ & $-0.02 \%$ \\
PP\&E (low - high) & $-0.33 \%$ & $-0.12 \%$ & $-0.09 \%$ \\
Dividends (nonpayer - payer) & $-0.43 \%$ & $-0.10 \%$ & $-0.17 \%$ \\
Age (young - old) & $-0.35 \%$ & $-0.15 \%$ & $-0.15 \%$ \\
Average Effect of & $-0.30 \%$ & $-0.08 \%$ & $-0.16 \%$ \\
Sentiment on Hedge & & & \\
N & 31,360 & 31,360 & 268,504 \\
\hline
\end{tabular}

This table presents the effect of lagged monthly sentiment and firm characteristics on market-adjusted returns, controlling for size, book-to-market, and momentum. See Table 2 for variable definitions. All firm characteristics are binary variables as previously described. The first column displays the effect of a one-decile increase in lagged sentiment on guidance window returns. The second column displays the effect of a one-decile increase in lagged sentiment on returns during the eighteen trading days outside of the guidance window. The third column displays the effect of a one-decile increase in lagged sentiment on monthly returns for months in which guidance is not issued (all months during the 1996-2006 sample period for the same firms during which no management guidance was issued). 
Table 5

The Effect of Sentiment on Earnings Announcement Window Returns

\begin{tabular}{|c|c|c|c|c|c|c|c|}
\hline & \multicolumn{7}{|c|}{ Dependent Variable: EACAR $(-1,+1)$} \\
\hline & Size & Volatility & Earnings & $R \& D$ & PP\&E & Dividends & Age \\
\hline $\begin{array}{l}\text { Preempted } \\
\text { Sample } \\
n=25,577\end{array}$ & & & & & & & \\
\hline $\begin{array}{c}\text { Sentiment* } \\
\text { Characteristic }\end{array}$ & $\begin{array}{l}0.0007^{* *} \\
(0.0003)\end{array}$ & $\begin{array}{c}-0.0011^{* *} \\
(0.0005)\end{array}$ & $\begin{array}{c}-0.0026 * * * \\
(0.0007)\end{array}$ & $\begin{array}{l}-0.0004 \\
(0.0004)\end{array}$ & $\begin{array}{l}-0.0004 \\
(0.0005)\end{array}$ & $\begin{array}{c}0.0004 \\
(0.0004)\end{array}$ & $\begin{array}{c}0.0001 \\
(0.0005)\end{array}$ \\
\hline $\begin{array}{c}\text { Non-Preempted } \\
\text { Sample } \\
n=86,158\end{array}$ & & & & & & & \\
\hline $\begin{array}{l}\text { Sentiment* } \\
\text { Characteristic }\end{array}$ & $\begin{array}{c}0.0003 \\
(0.0002)\end{array}$ & $\begin{array}{l}-0.0006 \\
(0.0004)\end{array}$ & $\begin{array}{l}-0.0006 \\
(0.0005)\end{array}$ & $\begin{array}{l}-0.0002 \\
(0.0004)\end{array}$ & $\begin{array}{c}0.0002 \\
(0.0003)\end{array}$ & $\begin{array}{l}0.0006^{*} \\
(0.0003)\end{array}$ & $\begin{array}{c}0.0004 \\
(0.0004)\end{array}$ \\
\hline
\end{tabular}

This table presents regression results that test the effects of firm overvaluation in periods of low and high sentiment on earnings announcement window returns after controlling for size, book-to market, and momentum. The Preempted Sample includes a sample of firms that issued guidance prior to the earnings announcement. The Non-Preempted Sample includes a sample of firms that did not issue guidance prior to the earnings announcement. Each cell reports the coefficient on sentiment interacted with the firm characteristic. $\operatorname{EACAR}(-1,+1)$ is the market-adjusted 3 day return centered around the earnings announcement date. Sentiment is the decile-ranked MCRC sentiment index in the prior month. See Table 2 for variable definitions. When interacted with Sentiment, Size, Volatility, PP\&E, and Age are coded as one if above the median, and zero otherwise, while Loss, $R \& D$, and Dividends are coded as a one when present and zero when absent. Robust standard errors clustered by month are displayed in parentheses. Coefficients marked with a $* * *$, or $* * *$ are significant at $\mathrm{p}<.10, .05$, or .01 , respectively. 


\section{Table 6}

\section{The Effect of Sentiment on Market Reaction to Positive and Negative Guidance Surprises}

\begin{tabular}{lc}
\hline & Dependent Variable: Car(-1,+1) \\
\hline Sentiment & $-0.0022^{* * *}$ \\
& $(0.0006)$ \\
PosSurp & $0.0469^{* * *}$ \\
& $(0.0037)$ \\
Sent*PosSurp & $0.0028^{* * *}$ \\
& $(0.0010)$ \\
NegSurp & $-0.0668^{* * *}$ \\
& $(0.0056)$ \\
Sent*NegSurp & $-0.0064 * * *$ \\
& $(0.0011)$ \\
Observations & 31,360 \\
R-squared & 0.182 \\
\hline
\end{tabular}

These regressions test the effects of a positive or negative surprise in periods of low and high sentiment on guidance window returns after controlling for size, book-to-market, and momentum. $C A R(-1,+1)$ is the market-adjusted 3 day return centered around the earnings guidance issuance date. PosSurp is a binary variable equal to one if the earnings guidance is higher than the prior analyst consensus forecast, and zero otherwise. NegSurp is a binary variable equal to one if the earnings guidance is lower than the prior analyst consensus forecast, and zero otherwise. Sentiment is the decile-ranked MCRC sentiment index in the prior month. Robust standard errors clustered by month are displayed in parentheses. Coefficients marked with $\mathrm{a} *{ }^{* *}$, or $* * *$ are significant at $\mathrm{p}<.10, .05$, or .01 , respectively. 


\section{Table 7}

\section{The Effect of Investor Myopia on Guidance Decisions}

\begin{tabular}{lccc}
\hline & $\operatorname{Pr}($ Disclose $=1)$ & $\operatorname{Pr}($ NegSurp=1) & $\operatorname{Pr}($ PosSurp=1) \\
\hline \multirow{3}{*}{ Size } & $0.2090^{* * *}$ & $-0.1510^{* * *}$ & $-0.0595^{* * *}$ \\
BTM & $(0.0106)$ & $(0.0124)$ & $(0.0153)$ \\
& $-0.1020^{* * *}$ & 0.0125 & 0.0459 \\
Momentum & $(0.0211)$ & $(0.0336)$ & $(0.0488)$ \\
& $-0.3730^{* * *}$ & $-1.1580^{* * *}$ & $0.9850^{* * *}$ \\
Sentiment & $(0.0511)$ & $(0.0735)$ & $(0.0620)$ \\
& $-0.0714^{* * *}$ & $0.0362^{* * *}$ & $-0.0378^{* * *}$ \\
Transient & $(0.0138)$ & $(0.0130)$ & $(0.0146)$ \\
& $0.4800^{* * *}$ & $0.1680^{* *}$ & $0.1610^{* *}$ \\
Sent*Transient & $(0.0360)$ & $(0.0722)$ & $(0.0696)$ \\
& $-0.0301 * * *$ & $-0.0271 * *$ & 0.0017 \\
Observations & $(0.00663)$ & $(0.0126)$ & $(0.0132)$ \\
R-Squared & 283,936 & 30,842 & 30,842 \\
\hline
\end{tabular}

These logit regressions test the effects of sentiment and transient institutional investor holdings on firms' guidance decisions after controlling for size, book-to-market, and momentum. Disclose is a binary variable equal to one if the firm issued guidance prior to the earnings announcement. PosSurp is a binary variable equal to one if the earnings guidance is higher than the prior analyst consensus forecast, and zero otherwise. NegSurp is a binary variable equal to one if the earnings guidance is lower than the prior analyst consensus forecast, and zero otherwise. Sentiment is the decile-ranked MCRC sentiment index in the prior month. Transient is a binary variable equal to one if the level of transient institutional investor holdings is above the median, and zero otherwise. Robust standard errors clustered by month are displayed in parentheses. Coefficients marked with $\mathrm{a}^{*}, * *$, or $* * *$ are significant at $\mathrm{p}<.10, .05$, or .01 , respectively. 